\title{
MONOPARENTALIDA
}

FEMININA SUSTENT PELO EXTRATIVIS DA MANG 


\section{MONOPARENTALIDADE FEMININA SUSTENTADA PELO EXTRATIVISMO DA MANGABA}

B I A N C A FERREIRA LIMA

UNIVERSIDAdE FEDERAL do PARÁ

DALVA MARIA DA MOTA

EMBRAPA AMAZÔNIA ORIENTAL 


\title{
MONOPARENTALIDADE FEMININA SUSTENTADA PELO EX- TRATIVISMO DA MANGABA
}

\section{Resumo}

Neste artigo, refletimos sobre mulheres chefes de famílias que praticam o extrativismo da mangaba sustentando a reprodução sociocultural de seus grupos. Buscamos, a partir de suas trajetórias, desvendar os fluxos migratórios, a vulnerabilidade na juventude e a segurança socioeconômica encontrada no extrativismo, aliados com a monoparentalidade. A pesquisa foi realizada na Vila Paca - Ilha de Marajó. Observações e entrevistas constaram dentre os procedimentos de pesquisa. As conclusões mostram que o extrativismo da mangaba é uma atividade ancestral praticada por mulheres e crianças, proporcionando autonomia do tempo, do trabalho e dos recursos monetários.

Palavras-Chave: Mulheres extrativistas de mangaba, chefia domiciliar feminina, Ilha do Marajó.

\section{FEMALE MONOPARENTING SUSTAINED BY THE EXTRACTI- VISM OF MANGABA}

\begin{abstract}
In this paper we reflect on women heads of families who practice the extractivism of mangaba, supporting the sociocultural reproduction of their groups. From their trajectories, we seek to unravel the migratory flows, the vulnerability in the youth and the socioeconomic security found in the extractivism, allied with the monoparenting. The research was held at Vila Paca - Marajó Island. Observations and interviews were included among the research procedures. The conclusions show that the extractivism of mangaba is an ancestral activity practiced by women and children, providing time, work and income autonomy.
\end{abstract}

Keywords: Mangaba extractivist, women Female household leadership, Marajó Island. 


\section{MONOPARENTALIDAD FEMENINA SOSTENIBLE POR EL EX- TRATIVISMO DE LA MANGABA}

\section{Resumen}

En este artículo, reflexionamos sobre mujeres jefas de familias que extraen mangaba de manera sostenible para la reproducción sociocultural de sus grupos. Buscamos, a partir de sus trayectorias, desentrañar factores como los flujos migratorios, la vulnerabilidad en la juventud y la seguridad socioeconómica ligada a la actividad extractiva, asociados con la monoparentalidad. La investigación se realizó en Vila Paca - Isla de Marajó. Las observaciones y entrevistas se destacan entre los procedimientos de investigación. Las conclusiones muestran que el extractivismo de la mangaba es una actividad ancestral practicada por mujeres y niños, que proporciona autonomía del tiempo, del trabajo y de los recursos monetarios.

Palabras clave: Mujeres extractivas de mangaba, Jefatura domiciliaria femenina, Isla de Marajó.

Bianca Ferreira Lima

biaflorestaa@gmail.com

Dalva Maria da Mota

dalva.mota@embrapa.br 


\section{INTRODUÇÃO}

Neste trabalho, temos como objetivo refletir sobre a trajetória de mulheres chefes de famílias e extrativistas de mangaba, moradoras de uma comunidade na Ilha do Marajó (PA). Sendo assim, buscamos a partir da trajetória dessas mulheres desvendar similitudes e diferenças no que diz respeito aos fluxos migratórios, a situação de vulnerabilidade destas mulheres na juventude e a possível segurança socioeconômica encontrada na prática do extrativismo aliando esses elementos de vida e trabalho com a monoparentalidade feminina.

Os estudos que tratam da monoparentalidade feminina ou mulheres chefes de família têm amadurecido academicamente ao tomarem como referencial os marcos teóricos de gênero, iniciados nos anos 1970 e aprofundado nos anos seguintes (Barroso 1978; Neves 1985; Woortmann 1987; Bruschini 1998; Scott 2002; Woortmann, 2010), tendo como motivação o aumento estatístico de domicílios chefiados por mulheres a partir dessa década. Todavia, observamos que as análises sobre monoparentalidade feminina, até os dias atuais, concentram-se em estudos relacionados a zonas urbanas (Mendes 2004; Carloto 2005; Cúnico \& Arpini 2014) e alguns poucos sobre mulheres agricultoras (Galizoni \& Ribeiro s/d). Isso pode ser reflexo do maior número de domicílios chefiados por mulheres nas zonas urbanas $(39,3 \%)$, enquanto na área rural essa proporção é de 24,8\% (Alves 2014).

Em contrapartida, poucos são os estu- dos sobre mulheres chefes de família que exercem a atividade extrativista e, menos ainda, quando se trata de mulheres extrativistas que vivem na região Norte do país.

No geral, observamos nos estudos a correlação entre a monoparentalidade feminina e o fenômeno de feminização da pobreza. Neste sentido, reforçamos a crítica de Macedo (2008) sobre a tendência em relacionar diretamente o "aumento" da chefia domiciliar feminina com o fenômeno da feminização da pobreza "que veem estas mulheres como as mais pobres entre os pobres" (Macedo 2008:389). De acordo com a autora, as mulheres são de fato as mais vulneráveis em nosso sistema capitalista. Todavia, não é o fato de chefiarem seus domicílios que as tornam mais pobres, e sim uma série de fatores estruturais, tais como ser a única responsável pela reprodução social de seu domicílio, baixos salários comparados aos de homens, a falta de oportunidade de estudo, a migração, a maternidade precoce, entre tantos outros.

Analisar como estas mulheres aliam a condição de extrativistas à monoparentalidade é o nosso desafio neste artigo. Focaremos no caso das mulheres chefes de domicílios em uma localidade na Ilha do Marajó (PA) que dependem do extrativismo de mangaba para garantir o aprovisionamento dos seus grupos domésticos, mas que não são proprietárias das terras onde estão localizadas as mangabeiras.

A pesquisa foi realizada no povoado Vila Paca, localizado no distrito de Joanes, que faz parte do município de 
Salvaterra, Ilha do Marajó (Pará). A metodologia privilegiou a abordagem qualitativa com observações (reuniões, coleta da mangaba, rotina doméstica) e entrevistas (com questões abertas e semiestruturadas, com as mulheres extrativistas de mangaba moradoras da Vila Paca e com membros de seus grupos domésticos. Atores de localidades adjacentes que praticam o extrativismo também foram entrevistados.

O artigo está estruturado em quatro partes: além da introdução, o segundo tópico traz uma descrição sobre o local de vida e trabalho das mulheres extrativistas chefes de família, a partir de narrativas locais que abarcam os mitos de origem e os aspectos socioambientais da região. No tópico três, fazemos uma reflexão sobre a trajetória das mulheres extrativistas de mangaba, da juventude à monoparentalidade feminina e como esse caminho percorrido pelas mulheres tem no extrativismo da mangaba uma possível segurança familiar. Por fim, nossas conclusões.

\section{NARRATIVAS SOBRE A ORIGEM DO LUGAR}

A Ilha do Marajó, em especial o distrito de Joanes, abriga histórias de seres "encantados", oriundos de uma sociedade indígena, deixando em herança, para os que hoje habitam e estudam a Ilha, os tesos e as cerâmicas marajoaras (Schaan 2002) espalhados em diferentes áreas, constituindo os sítios arqueológicos. $\mathrm{Na}$ Vila de Joanes, alguns estudos arqueológicos já foram realizados e com certa frequência ouvimos relatos de moradores que fazendo reformas em suas casas e terrenos encontraram os "cacos" de cerâmicas marajoaras.

Além dos indígenas, há forte presença da cultura negra, trazida pelos africanos no período da escravidão. O estudo de Cardoso (2008) realizado no município de Salvaterra, na comunidade quilombola de Bairro Alto, aponta para escassez de dados históricos, verificados também em outras regiões do país. Isso nos influencia a perceber como pouco frequentes são as pesquisas acadêmicas sobre os negros na Amazônia, relacionadas à suposta convicção de que pequenos contingentes de africanos foram destinados para esta região.

Tal miscigenação cultural incentivou a existência dos mitos e de histórias que ajudam a população local entender a formação daquela região e definir regras de uso do território, reinventadas e contadas de geração a geração. Para Cardoso (2008), essas são fontes propulsoras nas lutas pelo reconhecimento, junto ao Estado, de suas formas de vida e de minimizar os conflitos com espoliadores de terras.

"As construções sobre o território são variadas. Ele é espaço de investimento e circunscrição da organização social do grupo numa base física, onde se materializam as relações entre si, com outros, e, quase sempre, definindo um conjunto de crenças no sobrenatural, no mítico" (ibid: 55).

Neste sentido, um dos mitos que compõe as narrativas é a história da cobra grande, responsável pela formação dos igarapés que limitam o distrito de Joanes com o de Monsáras e Jubim, também descrita por Schaan (2011). 
Segundo o relato dos moradores locais, os igarapés foram formados por duas cobras grandes que moram no subsolo e que durante a tentativa frustrada das autoridades locais em construir uma estrada, entre Joanes e o povoado de Água Boa, estas cobras, originárias da Ilha do Cavalo, se revoltaram e removeram a terra. Como narram os entrevistados:

"Ali era uma estrada comum, aí o que acontece... depois que quiseram melhorar a estrada, colocaram aterro e tiraram a terra para colocar uma tubulação. Aí, no outro dia, quando amanheceu, tava uma vala imensa, quanto mais colocavam terra, mais aumentava a vala... era um serviço sem fim” (L.E., 52 anos, pescador nascido e criado em Joanes).

Aí tem a história que a cobra saiu de lá... se aborreceu (O.M., 67 anos, artesã, nascida e criada em Joanes). Não, mas antes disso. Quando foi para sair, assim, a cobra, ela morava numa ilha, a Ilha do Cavalo... Mas ouvi dizer que ela não saiu, só se mexeu. (M.L, 32 anos, artesã e funcionária do sistema de abastecimento de água de Joanes, nascida e criada em Joanes).

Não, ela saiu sim, porque quando amanheceu o dia, tava duas valas, uma para um lado e outra para outro. Porque vai assim, uma para um lado e outra para outro, que se encontra em um lugar. Porque é alto na capoeira, ali escorre aquela água, é limpinha a água lá. Ela vai pelo Iacanga [igarapé local - grifo nosso]. A outra parte é naquela mata que tem aqui por trás, ele vai para o mar, pela terra. A cobra é muito grande... Há uns vinte anos atrás viram essa cobra na estrada, ela é imensa. Saiu muita cobra, as outras foram para o mato, mas uma ficou. Tem parte no igarapé que é areia cheio de peixinho, mas tem outra parte do igarapé que você não vê, vai dá no igarapé de Água Boa. Ele vem direto e dá em Água Boa e vara na praia. O do Limão é diferente, ele já dá lá em cima no Guajará. Aqui tem história de encantamento e é verídico mesmo. O pessoal fala que nesse tempo ela apareceu e era para alguém ter coragem e cortar a cabeça dela para sangrar, mas ninguém teve coragem e o povo fez foi correr com medo dela. Joanes vai da ponta de redenção até Cruanã. $\mathrm{O}$ Cruanã que faz divisa com Jubim. Esses povoados que tem aí, tudo é parte de Joanes, eles querem apartar, não sei porque, mas tudo faz parte daqui. Até o Pingo D’água fazia parte daqui’' (L.E., 52 anos, pescador nascido e criado em Joanes).

Entendemos a narrativa como "pano de fundo" de um discurso que sustenta, para estes povos, noções de territorialidade, definida por Little (2002:3) como "esforço coletivo de um grupo social para ocupar, usar, controlar e se identificar com uma parcela específica de seu ambiente biofísico, convertendo-a assim em seu "território". Ainda de acordo com o autor:

"Outro aspecto fundamental da territorialidade humana é que ela tem uma multiplicidade de expressões, o que produz um leque muito amplo de tipos de territórios, cada um com suas particularidades socioculturais. Assim, a análise antropológica da territorialidade também precisa de abordagens etnográficas 
para entender as formas específicas dessa diversidade de territórios. No intuito de entender a relação particular que um grupo social mantém com seu respectivo território, utilizo o conceito de cosmografia (Little 2001), definido como os saberes ambientais, ideologias e identidades coletivamente criados e historicamente situados que um grupo social utiliza para estabelecer e manter seu território. A cosmografia de um grupo inclui seu regime de propriedade, os vínculos afetivos que mantém com seu território específico, a história da sua ocupação guardada na memória coletiva, o uso social que dá ao território e as formas de defesa dele" (ibid: 4).

Neste contexto, as cobras grandes permitem que esses moradores expliquem com propriedade a formação dos igarapés, sendo esses na Amazônia de grande importância para o deslocamento dos moradores e de suas mercadorias, de um local a outro, e isto data de tempos pretéritos, onde quase não existiam estradas e veículos aptos a trafegar nelas. Os igarapés também são fontes de alimento, de água para consumo e, sobretudo, da delimitação física da região. Para esta temática, a interpretação pode ser bastante vasta, a depender do enfoque teórico mobilizado. Não iremos adentrar neste campo teórico, de todo modo caracterizamos esta como uma fonte de dados relevante, entendendo este mito como uma "unidade cultural comum", traduzida por Cardoso como "uma luta mais profunda, que implica em garantir a reprodução sociocultural do grupo no presente e no futuro, e prestar deferência aos antepassados" (Cardoso 2008:58).
Ainda no campo do que é visível e invisível, e que determina culturalmente algumas regras, encontra-se a santa, Nossa Senhora do Rosário, que "foi a padroeira dos negros escravos e forros" (Botelho 2009), e que nas histórias de católicos, e até mesmo de seguidores de outras religiões, é legitimada como operadora de milagres e proteção desta região. Em diferentes momentos e a partir de atores distintos escutamos histórias sobre a padroeira da região. Tais histórias atribuem a essa santa a proteção do local, do povo e dos recursos naturais que ali estão.

Pareceu-nos bastante curioso a associação feita entre a mangaba e o círio de Nossa Senhora do Rosário, no distrito de Joanes, explícito no seguinte depoimento:

"A mangaba, aqui é festa... vou contar logo da igreja, a festa de Nossa Senhora do Rosário, que costuma festejar no mês de novembro para Nossa Senhora do Rosário, tem a igreja dela aí. Eles a consideravam padroeira da Ilha de Marajó. Então comemoravam no mês de novembro. A senhora sabe o que eles faziam com a mangaba? Não consentiam - as autoridades do lugar - não consentiam que tirasse mangabas antes do mês de novembro. Que quando ia começar o mês de novembro, podiam tirar, vendiam para os, naquele tempo chamavam ambulantes, hoje chama de marreteiros, para eles irem vender em Belém, em Icoaraci, em Mosqueiro... E só tirava a mangaba quando tava se aproximando da festa da Santa, e o produto da venda era para ajudar na festa da Santa. Eles [os que vendiam] eram daqui mesmo, homens 
que se dedicavam aquele trabalho de comprar e de vender..." (M. dos S. M., 97 anos, grifo nosso).

Botelho (2009:116) afirma que "no Brasil, a devoção ao Rosário foi trazida, sobretudo, pelos jesuítas e teve, desde o início, os negros como a maioria de seus adeptos". Ainda de acordo com a autora, as festas religiosas como o círio celebrado nesta região, são momentos em que todas as pessoas de diferentes camadas sociais e até mesmo de religiões desfrutam juntas o mesmo espaço público.

A associação entre a mangaba e o círio de Nossa Senhora do Rosário está relacionada para os extrativistas locais, entre outras coisas, ao fato da área devoluta - o campo da mangaba - ser "terra de santa", conforme o depoimento que se segue:

"Eu acredito nisso... Acredito porque a juíza de Soure disse que, quando veio no Círio, aquela mulher [santa] tinha ido lá ao fórum para falar sobre as terras dela, porque aqui tem as terras do patrimônio de Nossa Senhora do Rosário. Joanes tem essa terra que passa lá, chama Baixa do Taquari. Então eu digo assim: quando chega uma pessoa que quer pisar no povo de Joanes ela não deixa... Num vê o que fizeram quando os de fora vieram tomar os campos daqui?" (D. E., 87 anos, benzedeira e raizeira, moradora da Vila de Joanes).

Marin (2009:218), em seu trabalho junto às comunidades quilombolas de Salvaterra, mostra que a "noção nativa de "terra de Santa", representa um domínio reconhecido para uma área fora do controle de grandes pro- prietários". Cardoso (2008:55) mostra que "de acordo com as regras locais, existem espaços designados a pessoas, entidades míticas e santos, e estes são regulados por um conjunto de práticas e representações que constituem uma ordem jurídica local".

Nas chamadas terras de santo, as formas de uso comum coexistem, no nível da imaginação dos moradores, com uma legitimação jurídica de fato desses domínios, onde o santo aparece representado como proprietário legítimo, a despeito das formalidades legais requeridas pelo código da sociedade nacional (Marin 2009: 219).

Neste sentido, de acordo com a crença dos extrativistas, aqueles que não respeitam as regras são "castigados" pela santa, sendo impossibilitados de coletar nesta área. Além dos moradores locais, a santa também intimida os forasteiros que tentam ou tentaram se apropriar da área, sendo que para estes, a falha pode ser fatal. E é neste sentido que nos deparamos com a proteção desta área, estabelecida pelas redes sociais locais e definida pela oralidade (criando assim tais normas e regras conforme depoimento citado acima de D.E. citado acima), nascida e criada na região e descendente de escravos.

Ainda de acordo com Marin (2009:218), "terras de santa" e também "terras de santo" constituem modalidades do sistema de uso comum.

Os sistemas de uso comum representam soluções elaboradas historicamente. Nesse sistema o controle da terra e dos recursos não é exercido de forma livre e individualmente por um grupo doméstico de peque- 
nos produtores diretos ou por um de seus membros. Para Almeida, tal controle é feito mediante "normas específicas instituídas para além do código legal vigente". As normas são acatadas de maneira consensual "nos meandros das relações sociais estabelecidas entre vários grupos familiares que compõem uma unidade social". Esses sistemas têm sido incorporados nas estratégias de organização social e de sobrevivência de grupos camponeses, por meio dos quais se asseguram (Ma$\operatorname{rin} 2009: 218)$.

Constatamos que na presença do que estamos chamando de "invisível" narrado nas histórias de encantados, como a da cobra grande e da santa padroeira, e na ausência do que "teoricamente" seria visível, como por exemplo, programas e projetos de fomento ao agroextrativismo local pelas instâncias governamentais competentes, as regras e normas para gestão do campo da mangaba são criadas e validadas tradicionalmente, corroborando com Diegues (2001:120):

"Estas formas tradicionais se revelaram adequadas para o uso sustentado dos recursos naturais durante largo período de tempo e se basearam na existência de um conjunto de regras e valores consuetudinários, através da "lei do respeito", e de uma teia de reciprocidades sociais" (Diegues 2001:120).

\section{A VILA PACA, O LUGAR DE VIVER E O CAMPO DA MANGABA, O LU- GAR DA SOBREVIVÊNCIA}

A Vila Paca está localizada no distrito de Joanes, município de Salvaterra e, juntamente com outras quatro localidades - Cururu-Grande; Ramal de água Boa, Água Boa e Joanes - estão inseridas no campo da mangaba. Esse é uma área devoluta, limítrofe com a Vila Paca e a Vila de Joanes, é de livre acesso, não possui cerca e está localizada as margens da PA-154, sentido oeste. Conforme exposto no tópico anterior, o campo da mangaba é uma área repleta de significados para os extrativistas da região, os quais orientam as regras e o modo de uso dos recursos naturais ali existentes. Além disso, é uma importante área para a prática do extrativismo, que sustenta diversas famílias na região, como é o caso das mulheres moradoras de Vila Paca.

O campo da mangaba apresenta vegetação típica de cerrado sensu strictu ou savana tipo parque, pouca declividade (áreas de planícies) e altitude elevada. "As árvores são mais espaçadas uma das outras, e tem muito capim", afirma Dona O.C.A., moradora e extrativista de mangaba da região.

No campo da mangaba (como é conhecida pelos moradores da região esta área) coabitam, junto às mangabeiras, outras espécies frutíferas de interesse econômico para população local, como o tucumã (Astrocaryum aculeatum), murici (Byrsonima crassifolia), bacuri (Platonia insignis), além de espécies de uso medicinal, como quaresmeira (Tibouchina aspera), lacre-branco (Vismia cayennensis), lixeira ou caimbé (Curatella americana). Segundo Almeida et al. (1998), as áreas onde predominam as mangabeiras possuem solos arenosos e de baixa fertilidade. 
A Vila Paca dista aproximadamente 12 $\mathrm{km}$ da sede do município de Salvaterra, na margem leste da PA - 154. Além do acesso para Água Boa e CururuGrande, a Vila Paca localiza-se também na passagem para a Vila de Joanes e para Salvaterra, margeando a PA-154 que é asfaltada e rota de ônibus de linha, que saem da Vila de Joanes com destino a Salvaterra ou ao Porto da Balsa em Camará e vice-versa (Figura 1). De formação recente, quando comparada às outras localidades inseridas neste campo da mangaba, tem aproximadamente 30 anos e foi fundada pela família Amador.

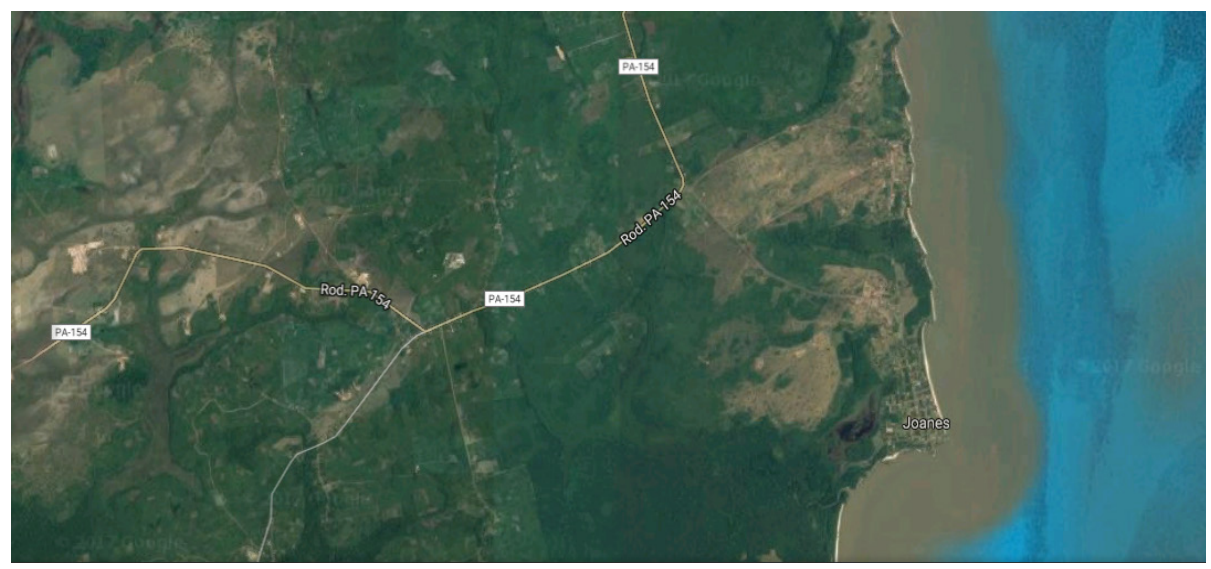

Figura 1- Mapa de localização da Vila Paca. Fonte: Google Maps. Montagem: Bianca Lima

Segundo depoimentos das filhas do fundador da Vila Paca, a família saiu de outra localidade no mesmo município - chamada Campina - para tentar melhores condições de vida nesta área, que foi doada ao pai, conforme depoimentos.

"A nossa vinda de lá da Campina, onde eu já te falei, para cá foi meu pai. Eu não sei te explicar bem direitinho porque eu já não convivia com eles, mas pelo que eles me contaram foi assim. Meu pai trabalhava muito lá e às vezes nada conseguia. Meu pai se dava muito com o prefeito de Salvaterra, daí foi lá e conversou com ele. Papai veio embora morar pra aqui, papai veio embora com a família. Vieram de lá morar praí, meu pai falou com o Sr. Aluiso um homem de Joanes e tirou um terreno aqui, aí, ó... Todinho... E fez uma casinha para ele, como a minha de barro e de palha. Depois que a casa aprontou eles vieram morar aqui. Depois que meu marido morreu foi que eu vim. Meu sobrinho que me deu um pedaço deste terreno para eu fazer minha casa" (A. A. R., 62 anos, extrativista de mangaba e moradora da Vila Paca).

Os motivos da saída dessa família da Campina para onde está fundada a Vila Paca, de certa forma, podem ser esclarecidos pelos argumentos apresentados por Marin em sua pesquisa sobre as comunidades quilombolas, apontando que "a abertura e pavimentação da 
Estrada PA-154 provocaram essa avalanche de indivíduos interessados nos terrenos" (Marin 2009:221).

"Caldeirão e Vila União-Campina foram profundamente modificadas com a construção da estrada, mas pode ser uma interpretação apressada pensar que essa intervenção nega o território quilombola e que estaríamos diante o avanço do modo de vida urbano. Em ambos os povoados a maioria identificouse como ocupação "na roça", apesar de terem comprometidas as condições reais de acesso às terras de cultivo" (ibid.).

A partir do desmembramento dessa família nuclear, formaram-se seis grupos domésticos os quais configuram a localidade. A chefia domiciliar de todos os grupos domésticos de Vila Paca é atribuída às mulheres que são parentes entre si, nascidas ali mesmo na região. A principal fonte de renda era na época de constituição da localidade, e continua sendo até os dias atuais, a agricultura de subsistência, a venda de mão de obra (trabalho de doméstica ou diaristas), o extrativismo animal e vegetal e mais recentemente os programas sociais (bolsa família e seguro defeso em alguns casos).

A configuração espacial da Vila Paca tem se dado na medida em que as necessidades vão sendo estabelecidas mediante a formação de novos grupos domésticos, para tanto, há o parcelamento da terra, antes uma só propriedade. As filhas e os primeiros netos que foram criados pelos fundadores da localidade têm sua parcela de terra. Já os netos mais novos e bisnetos possivelmente não terão as mesmas oportuni- dades com relação à terra, uma vez que não há espaço disponível nos padrões já estabelecidos, qual seja, uma casa e um pequeno espaço para a roça e para o terreiro. A posse da terra nesta localidade ocorre por meio da ocupação e, portanto, os moradores não possuem documentos comprobatórios de propriedade ou posse, mas uma memória social que atesta a condição de direito segundo as regras locais.

$\mathrm{Na}$ Vila Paca, às mulheres de cada grupo doméstico pertencem a casa, o terreiro e a roça. Aos homens pertence o externo à Vila, ou seja: o mar, a cidade e o "trabalho assalariado". Os espaços de uso comum na localidade são de domínio das mulheres, tanto as mais velhas como as mais jovens. Há também alguns espaços fora da localidade que são de uso misto, e não exclusivos dos moradores da vila, como o mangue e o campo da mangaba. Sendo que o último, os homens só utilizam para caçar ou para extrair madeira, destinada a construção de canoas, remos, cercas ou telhados, atividades que são esporádicas.

Sobre o espaço físico da localidade, os domicílios assumem a configuração espacial retilínea, onde cinco localizam-se lado a lado e um, construído mais recentemente, situa-se em frente aos demais. Esses domicílios foram formados nos últimos trinta anos, e na medida em que os grupos domésticos foram se constituindo o parcelamento da terra foi sendo realizado para os filhos e primeiros netos do casal fundador. Ao longo do tempo, ocorreram modificações sociais e estruturais, que conforme assinala Woortmann (1992: 
4) são construtoras da mesma temporalidade histórica.

Cada grupo doméstico possui uma área de terra, denominada "terreno", com aproximadamente $1500 \mathrm{~m}^{2}$, que abriga a casa, o terreiro e a roça. As casas são quase todas de tijolos e sem reboco. Três contam com banheiro interno, duas têm o banheiro ao fundo na área externa a casa, e uma ainda não possui banheiro. Em todas as casas a cozinha é uma construção anexa (externa), sendo coberta por telhas de amianto ou palha e sem paredes. É este o espaço escolhido pelas mulheres para conversas durante uma ou outra visita, na qual sempre é servido um café feito no fogão à lenha. As frentes das casas são delimitadas por cercas e portão de madeira e em muitas encontram-se placas anunciando a venda de frutos e/ou da polpa de mangaba.

\section{MONOPARENTALIDADE FEMININA}

Conforme já mencionado, na Vila Paca todos os moradores têm relação de parentesco e/ou compadrio. Sendo assim, a Vila é formada por seis grupos domésticos, dos quais, apenas um é chefiado por um homem e a mulher. Nos demais são as mulheres que assumem o compromisso pela sobrevivência dos membros do grupo. A população total é de 25 pessoas, e os grupos são compostos por no mínimo duas pessoas e no máximo seis pessoas, conforme distribuição apresentada na Tabela 1:

\begin{tabular}{|c|c|c|c|}
\hline GD & $\begin{array}{l}\text { Idade } \\
\text { da } \\
\text { infor- } \\
\text { mante }\end{array}$ & $\begin{array}{l}\text { N. de } \\
\text { habitantes } \\
\text { incluindo a } \\
\text { informante }\end{array}$ & $\begin{array}{l}\text { Relação dos } \\
\text { residentes com } \\
\text { a informante }\end{array}$ \\
\hline 1 & 62 & 3 & 1 filho e 1 nora \\
\hline 2 & 41 & 4 & 3 filhos \\
\hline 3 & 63 & 6 & $\begin{array}{l}2 \text { netos, } 1 \text { filha, } \\
1 \text { filho e } 1 \text { nora }\end{array}$ \\
\hline 4 & 56 & 4 & $\begin{array}{c}1 \text { neto, } 1 \text { filho, } \\
1 \text { nora }\end{array}$ \\
\hline 5 & 35 & 6 & $\begin{array}{l}1 \text { marido, } 3 \\
\text { filhos, } 1 \text { sogra }\end{array}$ \\
\hline 6 & 34 & 2 & 1 filha \\
\hline
\end{tabular}

Tabela 1 - Composição dos grupos domésticos da Vila Paca.

Fonte: Informações compiladas por Bianca Lima.

Segundo Berquó (2001), a chefia feminina corresponde a várias situações e possui vários significados, para compreendê-la é necessário entender o ciclo evolutivo dos grupos domésticos, desafio que nos propomos alcançar neste artigo.

Garcia Jr. (1983), nos fornece um importante pressuposto no que tange os princípios das relações entre os grupos domésticos, afirmando que: as relações de solidariedade entre os membros de uma mesma família, na produção doméstica, são de outra natureza (econômica e social), e diferem de processos de trabalho em que as relações de produção são estabelecidas por salários (Garcia Jr. 1983).

A dinâmica dos grupos domésticos estudados está diretamente relacionada a dois aspectos que consideramos fundamentais. O primeiro, trata das relações internas ao domicílio e abarca a categoria chefe domiciliar feminina, para qual Carvalho (1998) distingue três tipos: a) aquela que se define pela ausên- 
cia do parceiro sem necessariamente acontecer a manutenção feminina; b) aquela em que há a ausência masculina e a manutenção feminina e c) aquela em que há a manutenção feminina, não implicando necessariamente a ausência masculina. Nesse estudo há predominância do tipo b, uma vez que em três domicílios a chefia feminina é atribuída a viuvez, em dois a ausência de marido e em um domicílio a chefia é compartilhada entre o casal.

O segundo aspecto diz respeito às relações estabelecidas inter grupos domésticos, sustentado neste caso, pelos laços de parentesco, vizinhança e compadrio. As mulheres, por serem as que mais utilizam desta prerrogativa, tanto são sujeitos como objetos do sistema de ajuda mútua e cooperação, desenvolvido na localidade, o que permite articular a esfera produtiva e reprodutiva. Assim, criam condições, ainda que precárias do ponto de vista do acesso à saúde, educação e políticas afirmativas, para garantir a sobrevivência dos membros da família.

Constatamos que na Vila Paca os vizinhos e parentes são aliados importantes para a execução de boa parte das tarefas domésticas e produtivas, tais como: o cuidado com as crianças; divisão de alimentos excedentes (oriundos da caça ou da pesca); aproveitamento da ida de alguém à cidade para uma carona ou para encomendar algo necessário (compra de remédios); mutirões (construção de casa, coleta e fabrico de polpas de frutas); a organização de festejos na localidade e a fabricação de farinha de mandioca.
As mulheres são maioria na localidade (11 homens e 14 mulheres) e na organização local é atribuição feminina o zelo pelas estruturas comunitárias (limpeza da capela, monitoramento do sistema de água e de energia, as decisões sobre o local adequado para novas construções) e pela ordem social (ministram aulas de catequese na localidade para as crianças da vila; estabelecem as regras e normas de funcionamento da localidade, como por exemplo, datas e logística para as festas de santo, momento de fazer a farinhada), conforme pode ser exemplificado na fala de uma entrevistada:

"Se surge alguma coisa aqui, somos nós mesmas que resolvemos. A senhora viu que cortaram nossa água aqui por dois dias, se num fosse a D. ir lá em Salvaterra chamar os homens para resolver, a gente ia ficar aqui, naquela situação. Mesmo os homens que moram aqui, tudo trabalham fora, então somos nós mesmas que decidimos negócio de escola, de comida, de fruta, de criação. Vamos pro mangue, vamos atrás de caça, de fazer caieira... Ah! Mana, num tem jeito, de tudo a gente é obrigada a fazer, só Deus mesmo" (F.A., 57 anos, moradora da Vila Paca).

A participação dos homens adultos irmãos, tios e filhos das chefes de família - nas tarefas que dizem respeito à localidade ocorrem mais explicitamente em momentos que há necessidade de mediação junto aos negociantes ou comerciantes para aquisição de bens duráveis, tendo em vista que são eles que estão aptos a conduzir veículos, tanto para o transporte de 
pessoas como das mercadorias adquiridas e, principalmente pelo fato de ter maior treinamento, dada a experiência em ambientes públicos, para negociar mercadorias.

É interessante observar na Vila Paca, sob o ponto de vista das mulheres, o grupo doméstico é tratado tanto como unidade de consumo como de trabalho. Entretanto, sob o ponto de vista dos homens, o grupo doméstico é a unidade residencial, ainda que tais homens tenham ali obrigações econômicas para com a família, contudo não é neste espaço que realizam o trabalho. A compreensão das mulheres coincide com a de Heredia (1979), amparado no legado de Chayanov (1974), para quem a unidade de produção e consumo são coincidentes nos grupos camponeses.

Em três domicílios (50\%), observamos que o filho homem reside na casa da mãe, mesmo quando já tem família constituída. Nos outros três domicílios (50\%), os filhos homens ainda não são casados e nem têm filhos. A maioria dos homens, ou seja, os filhos das chefes de família aptos a trabalhar ${ }^{2}$, se ocupa com atividades fora da localidade, dedicando-se a prestação de serviços ou assalariamento, como pedreiros, marceneiros ou pescadores, em outras localidades ou nas cidades de Salvaterra e Belém. Somente um rapaz (17 anos) dedica-se a agricultura tendo uma área de roçado, em outra localidade, com maior predominância de abacaxi. Este caso é uma exceção, pois seu pai biológico, que não reside com a família, doou a área e o material vegetativo para que ele iniciasse sua produção.

\section{CAMINHOS PERCORRIDOS: TRAJE- TÓRIAS DE MULHERES EXTRATIVIS- TAS CHEFES DE FAMÍLIA}

A vivência destas mulheres, suas trajetórias e experiências dentro e fora da Vila Paca, onde residem atualmente, nos ajuda a entender os lugares e posições que elas ocupam no universo onde transitam. Dessa forma, entender o cotidiano e o uso do tempo, pelos membros dos grupos domésticos, é um caminho possível para chegar ao lugar reservado às mulheres na Vila Paca e quiçá reter o que Castro (2001) apresenta como sendo "a partir da identificação desse cotidiano, tecido pelos modos de vida, é possível entender aspectos fundamentais da compreensão singular dessas mulheres sobre o território" (Castro, 2001:17).

Para Costa (2001), cujo estudo envolveu mulheres trabalhadoras em madeireiras no município de Paragominas PA, a questão envolve três aspectos, os quais têm relação direta com a noção do tempo. O primeiro trata do tempo cotidiano; o segundo, do tempo biográfico, dos ciclos de atividade e da produção social das trajetórias femininas; e o terceiro é aquele de significação social das políticas de organização do tempo das mulheres.

"Em grupos de pessoas com baixo nível de escolaridade, habitando em municípios mais distantes do centro administrativo do Estado e desenvolvendo atividades industriais onde a existência de qualificação e de experiência profissional é praticamente inexistente, as atividades no trabalho e fora do trabalho se mesclam no tempo, não havendo 
uma separação nítida entre o tempo do trabalho e do tempo do lazer, ou de outras atividades sociais" (ibid:221).

Dialogando com as duas autoras acima citadas, trataremos de descrever de forma geral a rotina das mulheres na Vila Paca, as quais passam quase todo o tempo alternando suas atividades entre os afazeres domésticos e os afazeres ao redor da casa. Para elas o dia começa cedo. Às seis horas da manhã, o café já está no fogo e este é o horário de soltar as galinhas no terreiro, de preparar uma tapioca ou colher uma macaxeira para o desjejum. Depois que todos se alimentam, a maioria dos homens acima de 17 anos vai trabalhar e elas seguem nos seus afazeres, considerados por elas como serviço das mulheres.

Nesse rol de atividades se incluem lavar roupas e louças, varrer a casa, limpar o quintal, alimentar as galinhas, e iniciar o preparo dos alimentos para o almoço. Há uma variação nestas atividades matutinas, que obedece a um calendário agroextrativista local, pois em épocas da safra da mangaba, do bacuri ou em tempo de mariscar, o primeiro período do dia é reservado para estas atividades, geralmente isso ocorre no verão local (meses de julho a janeiro).

Quando se tem algo para resolver em Salvaterra, o tempo é cuidadosamente calculado por elas, que deixam tudo adiantado para poder pegar o transporte às nove horas e retornar às onze horas (último transporte do dia). Esses dias são, geralmente, no início de cada mês, quando necessitam ir ao banco receber os benefícios, pagar suas contas e comprar o rancho.
O almoço sempre está pronto por volta das onze horas e trinta minutos, pois as crianças da localidade estudam em outro povoado, chamado Pingo D’água, no período da tarde e pegam o ônibus disponibilizado pela prefeitura às treze horas. Essa escola vai do maternal até a quinta série do ensino fundamental, depois é necessário se matricular em Salvaterra para concluir o ensino fundamental e médio. Apesar de haver outras pessoas aptas a continuar os estudos, apenas um morador o fez. As chefes de família que mais estudaram, cursaram até a terceira série do ensino fundamental.

Os homens, que saem para trabalhar em Salvaterra ou em outros povoados, também retornam para almoçar em casa e geralmente são eles que trazem a mistura (peixe, carne, frango, caranguejo, camarão) para compor a refeição, quando as mulheres avisam que não tem "mistura do almoço". Não é costume comer hortaliças, diferente da farinha de mandioca que é alimento obrigatório para a maioria das pessoas. Apesar de existir uma boa variedade de frutas quase não se faz suco destas, sendo comum a utilização de sucos industrializados, vendidos em pó ou de refrigerantes, em momentos especiais. As frutas destinadas a alimentação familiar são consumidas ao acaso, ou seja, entre uma e outra andança, na medida em que são coletadas principalmente pelas crianças na localidade ou arredores. As frutas não têm um lugar privilegiado nas refeições familiares.

Depois do almoço, quando as crianças e os homens não estão na localidade, e depois de uma rápida descansada, as 
mulheres organizam a cozinha e realizam atividades diversificadas, todas voltadas para manutenção do domicílio ou da localidade. Entre estas atividades destaca-se a busca de lenha para fazer carvão, a capina do roçado que fica nos fundos da casa, e a queima do lixo, ou mesmo a caça de pequenos e médios animais, como tatu, paca, veado. É importante ressaltar que essas mulheres, quando necessário ou quando há oportunidade, caçam para compor a refeição. A caça, quando ocorre, é realizada no campo da mangaba. As atividades variam no decorrer do ano, uma vez que estão diretamente relacionadas às duas estações, o verão e o inverno.

Ao entardecer é a hora que as mulheres colocam as galinhas no poleiro, recolhem as roupas do varal, tomam seus banhos, se visitam para colocar a conversa em dia e combinam alguma atividade conjunta para o dia seguinte, quando é o caso. Servem o jantar por volta das dezenove horas e logo após vão assistir ao noticiário e às novelas. Após a última novela, todos já estão em suas redes prontos para dormir, horário em que só se ouve os latidos dos cachorros.

Um dos grupos domésticos tem um bar ao lado da casa. A construção é pequena e de alvenaria, no seu interior há freezers com bebidas, o balcão serve de divisória com o lado externo, delimitado por uma janela de madeira. $\mathrm{O}$ lado externo da construção é coberto por telhas de zinco, e tem uma mesa de sinuca e quatro jogos de mesas e cadeiras. Este estabelecimento abre aos sábados a partir das dezesseis horas e aos domingos o dia todo. Este é praticamente o único local de lazer da comunidade, frequentado pelos jovens e pelos mais velhos sem distinção de gênero. Geralmente aos domingos é promovido um bingo dançante nesse estabelecimento, e muitas pessoas de outras localidades vão até lá em busca de diversão. Durante a semana, o bar serve de quarto para um casal recém-formado, pertencente ao grupo doméstico, uma vez que na residência da mãe não há espaço e privacidade suficiente.

Sobre o lugar destas mulheres, refletimos acerca dos limites das esferas públicas e privadas nas quais estas transitam e constatamos que elas permanecem no espaço doméstico predominantemente, mesmo quando este era na capital do Estado, cidade de Belém, momento em que trabalhavam em casas de família. Ou quando, como diaristas, trabalham em restaurantes durante o veraneio na praia de Água Boa ou de Joanes, geralmente como auxiliares de cozinheira.

Constatamos que elas não participam, e nunca participaram, de nenhum grupo social organizado (associação, sindicato, movimento social, grupos religiosos). O universo social publicamente conhecido pelas mulheres da Vila Paca é o da casa, dos arredores, da localidade e do campo da mangaba. Os momentos de lazer são na própria comunidade, e sempre relacionados com algum festejo, no qual elas se divertem, bebem e comem, mas também são responsáveis por preparar e servir os alimentos e as bebidas e depois pela limpeza e organização do espaço. 


\section{A JUVENTUDE DAS MULHERES DE VILA PACA: TRAJETÓRIA E O CON- TEXTO DA MIGRAÇÃO}

As filhas mulheres, com idade acima de 17 anos, podem ou não residir com a mãe. Há dois casos na localidade em que as filhas moram no domicílio da mãe e em ambos os casos estas são mães solteiras, e consequentemente os filhos (netos da chefe da casa) também residem no domicilio. As mulheres, com apenas uma exceção, dedicam-se as tarefas de produção e reprodução na própria localidade, e, em um domicílio, a nora da chefa de família - que ainda não tem filho - trabalha como merendeira na escola de outro povoado.

A situação das mulheres jovens, que residem no domicílio da mãe, não é uma condição invejável e elas mesmas afirmam que a situação é transitória, atribuída ao desejo de arrumarem trabalho em casas de famílias, como domésticas, situação que já foi experimentada por elas, tendo retornado à vila após engravidarem. Sobre a experiência de trabalho como domésticas em casas de família na capital do Estado (Belém), cumpre mencionar que esse é um padrão que se repete desde as avós, fazendo parte de uma trajetória de idas e vindas sem lograr os objetivos iniciais (estudar e conseguir um bom emprego), conforme podemos observar na fala de uma moradora da Vila Paca:

"Quando eu vim para cá mesmo, eu estava com 51 anos, porque de lá da Campina eu fui embora para Belém, trabalhar em casa de família, porque meus pais são pobres e não tinham como dar meu luxuzinho, né? Eu desde a idade de 12 anos já trabalhei em casa de família. Meu pai e minha mãe ficaram. Depois que foram minhas irmãs. Já depois... Agora, que meu marido faleceu, foi que eu vim embora para cá. Aí que eu vim trabalhar com a polpa da mangaba, e aqui estou, trabalhando com a polpa da mangaba, quer dizer voltando a trabalhar com a mangaba" (A. A. R., 62 anos).

As mulheres jovens mostram insatisfação com o fato de não terem trabalho, de dar despesa para a mãe delas, tendo em vista as precárias condições materiais, e de ter pouca liberdade e autonomia, até mesmo na criação de seus filhos. Apesar das avós aceitarem a situação da filha como mãe solteira e contribuírem na criação de seus netos, existe uma certa tensão velada de ambos os lados e que de certa forma é esperada uma vez que as filhas ao saírem da casa dos pais não são instruídas a adotar métodos anticoncepcionais para evitar uma gravidez, na qual, a maioria das vezes, não contarão com o apoio do parceiro para criação dos filhos, caso isso ocorra. Segundo Woortmann e Woortmann (2004):

"Mães solteiras e grupos domésticos monoparentais com chefia feminina começaram a surgir com a migração para a cidade. Desaparecendo o controle exercido pela família e pela comunidade, relações sexuais não maritais, mesmo que não frequentes, podem conduzir a monoparentalidade" (Woortmann \& Woortmann 2004:46)

Em outro contexto, Stropassolas (2006), em seu trabalho sobre juventude rural e reprodução social da 
agricultura familiar, nos mostra que as relações de gênero e geração são geralmente carregadas de tensão e, ao mesmo tempo, de redefinição de valores e identidades. O autor problematiza a questão da jovem mulher rural, responsável pelo maior percentual de migração campo-cidade, muitas vezes estimuladas pela própria família para que as jovens procurem emprego ou estudo na cidade.

No caso da Vila Paca, as duas mulheres que retornaram à localidade apresentam certo constrangimento com a atual situação, explicado por Strapossolas (2006), pelo fato de que a experiência na cidade dificilmente permite que as mulheres retornem ao campo, porque não desejam reproduzir a condição social da mulher na agricultura. No caso da Vila Paca parece não ter havido alternativa, a não ser retornar para casa da família de origem, no interior.

Em 1978, Carmem Barroso publicou um artigo intitulado: "Sozinhas ou mal acompanhadas: a situação das mulheres chefes de família", momento em que a temática começava a ser discutida mais profundamente no Brasil (Neves 1985; Woortmann 1987). Em seu texto a autora já relacionava o fenômeno da chefia feminina ao fato das migrações, tanto de homens como de mulheres e questionava se esse era o fator primordial para a tendência apresentada nos dados censitários. A autora trabalha com dados dos censos da década de 50 à de 70 , para populações de regiões metropolitanas, período em que ocorre uma mudança no perfil da população brasileira, que passa de um país com maior concentração rural para urbana.
"Tem-se sugerido que a emergência das famílias chefiadas por mulheres são, em parte, o resultado da migração, sejam de homens que deixam sua mulher e filhos no local de origem, seja de mulheres jovens que migram sozinhas" (Barroso 1978:458).

Scott (2010), mais recentemente analisando os dados do FIBGE ${ }^{3}$ (2008), constata que:

"A partir da faixa etária de vinte anos, a presença feminina no campo diminui proporcionalmente mais rápido, enquanto os homens apresentam maior tendência de ficar no campo em cada faixa etária sucessiva" (Scott 2010:22).

O autor explica que tal fato se deve, em parte, aos adultos que ao evocarem tal categoria com fins de disciplinar principalmente as mulheres jovens, mais do que para elaborarem novas estratégias cotidianas, terminam por fortalecer a condição de migração das mulheres que geralmente vão viver exclusivamente de subempregos urbanos (ibid:29).

Corroborando com Scott (2010), tais questões relativas a gênero e geração reproduzem, na Vila Paca, este cenário conflituoso e de certa forma velado, o qual favorece a migração das mulheres jovens, que em um primeiro momento é justificada pela necessidade de estudo, mas por fim termina com o assalariamento dessas como domésticas em casa de famílias e sem condições de estudarem.

Conforme apresentado, as atuais chefes de família também migraram em sua juventude e, portanto, esse é um 
padrão que se repete de geração em geração. Um aspecto que consideramos importante é a compreensão de que é na atividade extrativista, principalmente da mangaba, que tais mulheres, tanto as chefes de família quanto as outras, obtêm uma segurança monetária, juntamente com a certeza de que ao menos em um período do ano poderão contar com uma renda certa, ao retornarem ao local de origem. Isso pode estar relacionado a diferentes fatores, entre eles o domínio da atividade, a flexibilidade de tempo para praticar a atividade, a autonomia para fazê-la uma vez que sozinhas ou acompanhadas podem obter os frutos - e a certeza que há possibilidade de negociação dos produtos, sejam eles in natura ou beneficiados como polpa.

\section{O EXTRATIVISMO DA MANGABA COMO ALTERNATIVA DE PRODU- ÇÃO E REPRODUÇÃO PARA AS MULHERES DE VILA PACA}

Se há predominância das mulheres nas atividades domésticas, o mesmo pode-se dizer das atividades agroextrativistas. Verificamos que as mulheres são as responsáveis pelo extrativismo das frutas, entre elas: a mangaba, o bacuri, o tucumã, o murici e pelo plantio de espécies agrícolas anuais, como milho, mandioca, melancia, maxixe e jerimum, e fruteiras, como a goiaba, o caju e a manga. A maior parte da produção extrativa é destinada à comercialização, diferente da produção dos roçados que é direcionada para o consumo familiar do grupo doméstico ou para trocas e presentes entre a vizinhança.
Os homens pertencentes ao grupo doméstico não participam do extrativismo de frutas ou das atividades do roçado, estes se dedicam com maior frequência ao trabalho assalariado, de pedreiro ou nos comércios de Salvaterra e da Vila de Joanes. Neste contexto, para a maior parte dos homens as atividades são ocasionais, ainda que os mesmos estejam sempre prestando serviços assalariados, não há contratos formalizados para estas atividades, o que não garante a permanência da mesma. Para além dos serviços assalariados, os homens esporadicamente praticam a pesca, em períodos que o assalariamento está em baixa.

As crianças desde cedo, a partir dos cinco anos de idade, acompanham as mulheres na etapa de coleta dos frutos, uma vez que na maioria dos casos suas mães não têm com quem deixá-las. Mota et al. (2011), tratando do extrativismo da mangaba, afirmam que está embutido nesta prática tanto a usual "ajuda", quanto o controle dos pais para com os filhos, contribuindo desta maneira na formação do caráter dos indivíduos. Sendo assim, consideramos que são esses os momentos em que os conhecimentos são repassados de geração a geração, conforme depoimento:

"Lembro que quando a mãe ia pro campo a gente tinha que ir, até mesmo porque ela não permitia que ficássemos dormindo. A gente acordava cedinho e ia simbora. Às vezes, ia só mesmo com café e farinha. Naquele tempo não tinha esse negócio de pão, bolacha, como tem hoje. E até mesmo os pais da gente era pobre, não tinha dinheiro e nem 
tinha as facilidades que tem hoje. A gente apanhava as mangabas no campo e quando era por volta das 11 horas já vinha voltando. Foi assim que aprendi, e esses aí ó [se referindo as crianças] vão também, tem que ir, porque a gente só pode deixar para eles o conhecimento que a gente tem, né?” (A. A. R., 62 anos, extrativista de mangaba e moradora da Vila Paca, grifo nosso).

Observamos que as meninas participam ativamente, muitas vezes subindo nas mangabeiras para retirar as mangabas, juntando os frutos caídos no chão e, aquelas mais atentas informam sobre árvores que estão "carregadas". Os meninos, quando vão ao campo, se atêm em pegar os frutos caídos no chão ou servir a água para os demais participantes da atividade. Mota et al. (2011) observaram situações semelhantes no nordeste brasileiro, e atribuem ao menor peso das crianças o fato de serem elas a subirem nas árvores, o que não prejudica a espécie com quebra de galhos. Para os autores, as crianças se alternam entre as brincadeiras e a iniciação do trabalho, assim como em outras atividades no espaço rural. As diferenciações que delimitam os afazeres de meninos aos de meninas começam a surgir na pré-adolescência, quando as posições de gênero são acentuadas na divisão sexual do trabalho.

O principal uso econômico da mangabeira na Vila Paca, e nos arredores, é o aproveitamento dos frutos para fazer polpas a serem congeladas. Nessa região as formas de acesso e uso dos recursos naturais (animais como vegetais) são diversificadas a depender da localização das moradias, o que determina a frequência e a intensidade do aproveitamento dos mesmos. Observamos que nas localidades que margeiam a Baía do Marajó há grande concentração de moradores dedicados a pesca, este é o exemplo da Vila de Joanes, de Água Boa e Cururu-Grande, diferentemente da Vila Paca e do Ramal de Água Boa, nos quais os moradores afirmam dedicarem-se mais ao extrativismo de frutas nativas como a mangaba e o bacuri, agricultura e caça.

Em algumas localidades, como a Vila Paca e a Vila de Joanes, as mangabeiras próximas as residências não são suficientes para atender a demanda, o que faz com que os extrativistas destas localidades se desloquem para coletar no campo da mangaba.

Já nas outras localidades: Água Boa; Ramal de Água Boa e Cururu-Grande a coleta de mangaba pode ser realizada in loco, pois a oferta supre a demanda.

As múltiplas atividades desenvolvidas pelas mulheres da Vila Paca nem sempre garantem a entrada de recursos monetários, mas certamente complementam a renda, uma vez que por meio de dinheiro ou de produtos agroextrativistas, da caça ou da pesca, são garantidas as condições necessárias para sobrevivência da família, tais como alimentação, vestimentas, remédios e algo para o lazer. Os benefícios recebidos pelo governo, com uma exceção apenas, são mensalmente a principal fonte de entrada monetária nos grupos domésticos. 


\section{REFLEXÕES FINAIS}

O objetivo do artigo foi fazer uma reflexão sobre as mulheres chefes de famílias, moradoras da Vila Paca, na Ilha do Marajó (PA), que praticam o extrativismo da mangaba sustentando a reprodução sociocultural de seus grupos.

Identificamos nesta pesquisa uma lacuna nos estudos sobre monoparentalidade feminina quando tomamos como referência famílias amazônicas que têm na prática do extrativismo uma importante atividade para subsistência de seus grupos domésticos. Observamos que na Vila Paca a chefia feminina dos domicílios ocorre pela ausência de maridos ou homens que assumam tal responsabilidade. Além disso, identificamos que o padrão de migração na juventude dessas mulheres extrativistas, na maioria das vezes, corrobora para a maternidade precoce sem apoio do companheiro (pai da criança). A análise da trajetória destas mulheres nos mostra que o espaço doméstico é o locus de seu trabalho produtivo e reprodutivo e, que a chefia familiar nem sempre é uma escolha e sim a única opção que resta.

Constatamos - conforme indicam as pesquisas sobre o tema e nossos dados empíricos - que as famílias chefiadas por mulheres são mais vulneráveis economicamente e socialmente. Neste contexto, concluímos que as mulheres extrativistas de mangaba têm consciência da vida de sacrifício, relacionada ao pouco acesso aos bens materiais e às oportunidades de ascensão social, não vendo na escolarização uma forma de crescimento econômico para seu gru- po, uma vez que a qualidade do ensino formal - que foram submetidas e que submetem seus filhos - não possibilita chegar à formação técnica ou universitária. Sendo assim, as mulheres extrativistas se esforçam em repassar a seus descendentes os conhecimentos sobre o uso e gestão dos recursos naturais, tais como aprenderam com seus pais, retratados em falas como essa: "é a única herança que podemos deixar para nossos filhos".

Identificamos que a atividade extrativista é realizada pelas mulheres com a ajuda das crianças e que as chefes de família são as principais responsáveis pelo trabalho doméstico e pela mobilização de recursos monetários para garantir a sobrevivência dos seus grupos domésticos, conciliando as atividades de casa com o assalariamento, o extrativismo e a agricultura de subsistência. Cabe à mulher - chefe do domicílio - $\mathrm{O}$ controle dos recursos, tanto os monetários como os demais. É ela quem decide o que comprar e quanto comprar, bem como se é o momento certo para sacrificar uma galinha para refeição, ou se é melhor caçar ou mariscar.

O extrativismo da mangaba é uma atividade que permite a gestão comum dos recursos naturais, e este fator é fundamental para existência destas mulheres extrativistas, uma vez que por meio da apropriação da natureza elas definem e auto regulamentam as estratégias, regras e acordos coletivos para o uso comum da terra e dos recursos naturais. Sendo assim, podemos afirmar que as mulheres extrativistas de mangaba são aliadas importantes para a garantia da conservação ambiental, pois 
seus modos de vida estão diretamente relacionados com este princípio. Não se trata de grupos ambientalistas, mas de povos e comunidades que retiram da natureza o sustento de suas famílias e que dependem da oferta sazonal de determinados recursos, principalmente a mangaba, para trabalhar.

Constatamos que o planejamento para utilização dos recursos é papel das mulheres chefes de família. São elas que controlam os montantes recebidos por meio da aquisição de alimentos, de materiais de higiene, de roupas. Também são as mulheres as principais responsáveis pelo planejamento de novas instalações nos domićlios, ainda que sejam os homens os executores. Verificamos que os papéis desempenhados pelas mulheres extrativistas da Vila Paca são bastante diversificados e exigem uma grande capacidade de conciliação, força e coragem por parte dessas mulheres para levar a cabo as iniciativas que garantem a reprodução de seus descendentes.

\section{NOTAS}

${ }^{1}$ Neste contexto a categoria de análise trabalho está relacionada a lugar externo a localidade onde é possível o assalariamento, sendo assim não se considera trabalho as atividades realizadas no interior da comunidade, sendo muito comum ouvir que ali, na Vila Paca, não se tem trabalho.

${ }^{2}$ Geralmente os maiores de 17 anos

${ }^{3}$ Fundação Instituto Brasileiro de Geografia e Estatística (FIBGE)

\section{REFERÊNCIAS}

Almeida, S. P. de; Proença, C. E. B; Sano, S. M.; Ribeiro, J. F. 1998. Cerrado: espécies vegetais úteis. Brasília: Embrapa Cerrados. Alves, C. 2014. Mais mulheres são chefes de familia, e jovens optam por ser mãe mais tarde. Disponível em: <http://g1.globo.com/ economia/noticia/2014/10/mais-mulheres-sao-chefes-de-familia-e-jovens-optam-por-ser-mae-mais-tarde.html>. Acesso em: 04 mar. 2017.

Barroso, C. 1978. Sozinhas on mal acompanhadas - a situação das mulheres chefes de família. ABEP, 1: p. 457-472. Disponível em: <http://www.abep.nepo.unicamp.br/ docs/anais/pdf/1978/T78V01A15.pdf $>$. Acesso em: 21 de abr. 2012.

Berquó, E. 2002. Perfil demográfico das chefias femininas no Brasil, in Gênero, Democracia e Sociedade Brasileira. Organizado por C. Bruschini, e S. G. Unbehaum. Editado por Editora 34 e coeditado por FCC, p 243-265.

Botelho, I. 2009. A festa de Nossa Senhora do Rosário: identidades construídas, identidades em construção, in Diversidade do campesinato: expressões e categorias: construções identitárias e sociabilidades. Organizado por E. P. de Godoi, M. A. de Menezes, e A. R. Marin. Editado por UNESP, pp. 113-136. Brasília, DF: Núcleo de Estudos Agrários e Desenvolvimento Rural. Disponível em: < $\underline{\text { http://www.reformaa- }}$ grariaemdados.org.br/sites/default/files/ Hist $\% \mathrm{C} 3 \% \mathrm{~B} 3 \mathrm{ria}^{2} \% 20$ social $\% 20 \mathrm{do} \% 20$ campesinato $\% 20$ no $^{2} 20 \mathrm{Brasil} \% 20-\% 20$ Diversidade $\% 20$ do $\% 20$ Campesinato $\% 20$ -\%20v.\%201.pdf>. Acesso em: 10 abr. 2012.

Bruschini, M. C. 1998. Trabalho das mulheres e mudanças no período 1985 - 1995. São Paulo: FCC/DPE. (Textos FCC, 17).

Cardoso, L. F. C. 2008. A constituição local: direito e território quilombola na comunidade de Bairro Alto, na Ilha de Marajó - Pará. Tese de doutorado, Departamento de Antropologia Social, Universidade Federal de Santa 
Catarina, Florianópolis, Brasil.

Carloto, C. M. 2005. Revista Virtual Textos \& Contextos, 4. Disponível em: <http://revistaseletronicas.pucrs.br/ojs/index.php/ fass/article/viewFile/994/774>. Acesso em: 12 abr. 2017.

Carvalho, L. M. S. 1998. A Mulher trabalhadora na dinâmica da manutenção e da chefia domiciliar. Revista Estudos Feministas 6(1):7-33.

Castro, E. 2001. Prefácio, in Mulheres da floresta amazônica: entre o trabalho e a cultura. Organizado por L. T. L. Simonian. pp. 1521. Belém: UFPA/NAEA.

Chayanov, A. V. 1974. La organización de la unidad económica campesina. Buenos Aires: Ediciones Nueva Visión. Disponível em: <https://pt.scribd.com/ document $/ 210404680 /$ Chayanov-La-organizacion-de-la-unidad-economica-campesina >. Acesso em: 10 jul. 2011.

Costa, M. J. J. 2001.Tempo e trabalho - uma análise sociológica do tempo: referencia ao uso do tempo pelas trabalhadoras da madeira, em Paragominas - PA, in Sociologia na Amazônia - Debates teóricos e experiências de pesquisa. Editora Universitária UFPA, pp. 217-242. Belém.

Cúnico, S.D., e D.M. Arpini. 2014. Família e monoparentalidade feminina sob a ótica de mulheres chefes de família. Aletheia. no.43-44 Canoas. 1413-0394. Disponível em: <http://pepsic.bvsalud. org/scielo.php?script $=$ sci arttext\&pid $=$ S1413-03942014000100004> Acesso em: 17 maio 2017.

Diegues, A. C. 2001. Repensando e recriando as formas de apropriação comum dos espaços e recursos naturais, in Espaços e Recursos Naturais de Uso Comum. Organizado por A. C. Diegues, e A. C. C. Moreira, pp. 97-124. São Paulo: NUPAUB/LASTROP-USP. Original: 1990.
Galizoni, F. M., e E.M. Ribeiro. Trabalho feminino na agricultura familiar do Alto Jequitinhonha, Minas Gerais. Disponível em: < $\underline{\text { http:// }}$ www.sober.org.br/palestra/12/090436. pdf>. Acesso em: 02 mar. 2017.

Garcia Júnior, A. 1983. Terra de trabalho. Editado por Paz e Terra. Coleção Estudos sobre o Nordeste 8. Rio de Janeiro.

Heredia, B. M. A. de. 1979. A morada da vida: trabalho familiar de pequenos produtores do Nordeste brasileiro. Rio de Janeiro. Editado por Paz e Terra.

Little, P. E. 2002. Territórios sociais e povos tradicionais no brasil: por uma antropologia da territorialidade. Séries Antropologia 332. Universidade de Brasília. 2002. $32 \mathrm{p}$.

Macedo, M. dos S. 2008. Mulheres chefes de família e a perspectiva de gênero: trajetória de um tema e a crítica sobre a feminização da pobreza. Caderno $\mathrm{CRH}$ 21(53):389-404. Disponível em: <http:// www.scielo.br/scielo.php?pid $=\mathrm{S} 0103-$ $-49792008000200013 \&$ script $=$ sci abstract\&tlng $=\mathrm{pt}>$. Acesso em:12 abr. 2017.

Marin, R. A. 2009. Quilombolas na ilha de Marajó: território e organização política, in Diversidade do campesinato: expressões e categorias: construções identitárias e sociabilidades. Organizado por E. P. de Godoi, M. A. de Menezes, e A. R. Marin. pp. 209-228. Brasília, DF: Núcleo de Estudos Agrários e Desenvolvimento Rural; UNESP. Disponível em: <http://www.reformaagrariaemdados.org.br/sites/default/files/ Hist $\%$ C $3 \%$ B 3 ria $\% 20$ social $\% 20$ do $\% 20$ campesinato $\% 20$ no $^{2} \% 20 \mathrm{Brasil} \% 20-\% 20$ Diversidade $\% 20$ do $\% 20$ Campesinato $\% 20$ -\%20v.\%201.pdf>. Acesso em: 7 abr. 2012.

Mendes, M. A. 2004. Mulheres chefes de domicílios em camadas pobres: trajetória familiar, trabalho e relações de gênero, in XIV Encontro Nacional de Estudos Popu- 
lacionais, $A B E P$, realizado em Caxambu - MG - Brasil, de 20- 24 de Setembro de 2004. Disponível em: < http://www.abep. nepo.unicamp.br/site eventos abep/pdf/ abep2004 787.pdf $>$. Acesso em: 05 abr. 2017.

Mota, D. M. da. 2011. As Senhoras da Mangaba, in A Mangabeira. As catadoras. $O$ extrativismo. Organizado por D. M. da Mota et al., pp. 95-127. Belém: Embrapa Amazônia Oriental; Aracaju: Embrapa Tabuleiros Costeiros.

Mota, D. M. da, et.al. 2009. Disputas pelo acesso aos recursos naturais: o dilema das mulheres catadoras de mangaba em Sergipe, in 33. Encontro Anual Da Associação Nacional de Pós-Graduação e Pesquisa em Ciências Sociais, Caxambu. Anais... Disponível em: <http://www.anpocs. org.br/portal $/$ index.php?option $=$ com wrapper\&Itemid=101 $>$. Acesso em: 21 out. 2011.

Neves, D. P. 1985. Nesse terreno galo não canta. Estudos do caráter matrifocal de unidades familiares de baixa renda, in $A n u$ ário Antropológico 83. Organizado por R. C. de Oliveira, pp. 199-220. Rio de Janeiro: Tempo Brasileiro; Fortaleza: UFC.

Schaan, D. P. 2002. De tesos e igaçabas, de indios e portugueses: arqueologia e história da ilha de marajó. Texto escrito especialmente para a exposição de cerâmica Marajoara do $\mathrm{Mu}$ seu do Forte do Castelo, Belém, PA. Disponível em: $<$ http://www.marajoara.com/ Arqueologia Historia da Ilha Marajo $>$. Acesso em 29 fev. 2012.

Schaan, D. P. 2011. Histórias da cobra grande, in Remando por Campos e Florestas: Memórias \& Paisagens dos Marajós. Organizado por D. P. Schaan, A. S. Pacheco, e J. F. Beltrão. Editado por Gknoronha, pp. 8394. Rio Branco.

Schmitz, H., D. M. da Mota, e L. F. C. e. Cardoso. 2010. Movimento das catadoras de mangaba: a conquista de uma identidade, in III Seminário Nacional e I Seminário Internacional Movimentos Sociais Participação e Democracia. Florianópolis. Anais... Núcleo de Pesquisa em Movimentos Sociais - NPMS. UFSC. Disponível em: < $\underline{\text { http:// }}$ www.catadorasdemangaba.com.br/publicacoes/texto-11.pdf>. Acesso em: 4 jul. 2011

Schmitz, H., D. M. Mota, e J. F. Silva Júnior. 2008. Conflitos sociais cercam as catadoras de mangaba, in Encontro da Associação Nacional de Pós-Graduaşão e Pesquisa em Ambiente e Sociedade (Anppas), 4, Brasília.

Scott, P.; Rodrigues, A. C.; Saraiva, J. das C. 2010. Onde mal se ouvem os gritos de socorro: notas sobre a violência contra a mulher em contextos rurais. In: Scott, P.; Cordeiro, R. e Menezes, M. (Org). Gênero e Geração em contextos rurais. Ilha de Santa Catarina: Ed. Mulheres, 2010. 480 p. p. 65-96 Scott, P. 2006. Gênero e Geração em contextos rurais: algumas considerações, in Gênero e Geração em contextos rurais. Organizado por P. Scott, R. Cordeiro, e M. Menezes. Editado por Mulheres, pp. 17-35. Disponível em: $<$ https://www.ufpe.br/fagesufpe/images/documentos/Livros Fages/genero $\% 20 \mathrm{e} \% 20$ gera $0 \% 20 \mathrm{em}^{2} \% 20$ contextos $\% 20$ rurais.pdf>. Acesso em: 14 abr.2017.

Scott, P. 2002. Mulheres Chefes de Família: abordagens e temas para as políticas públicas, in Pré-Evento Mulheres Chefes de Família: crescimento, diversidade e políticas, realizado em 4 de novembro de 2002, Ouro Preto-MG pela CNPD, FNUAP e ABEP. Disponível em: <http://www.abep.nepo. unicamp.br/XIIIencontro/Scott intro mulher chefe.pdf $>$. Acesso em: 10 mar. 2017.

Stropasolas, V. L. 2006. O trabalho no cotidiano dos jovens, in O Mundo rural no horizonte dos jovens. Organizado por Stropasolas 
V. L. pp. 243-311. Florianópolis: Editora da UFSC.

Woortmann, K., e E. F. Woortmann. 2004. Monoparentalidade e chefia feminina: conceitos, contextos e circunstâncias. Disponível $\mathrm{em}:<$ www.abep. nepo.unicamp.br /XIII encontro/woortmann.pdf $>$. Acesso em: 18 abr. 2012.

Woortmann, K. 1987. A Família das Mulheres. Rio de Janeiro: Tempo Brasileiro; Brasília: CNPq.

Woortmann, E. F. 2010. Prefácio, in Gênero e geração em contextos rurais. Organizado por P. Scott, R. Cordeiro, e M. Menezes. Ilha de Santa Catarina: Editora Mulheres. Disponível em: < https://www.ufpe.br/fagesufpe/images/documentos/Livros $\mathrm{Fa}$ ges/genero $\% 20 \mathrm{e} \% 20$ gera $\mathrm{o} \% 20 \mathrm{em} \% 20$ contextos $\% 20$ rurais.pdf> Acesso em: 14 abr. 2017.

Recebido em 10/06/2017

Aprovado em 02/08/2017 